\title{
Highly sensitive electrochemiluminescence displacement method for the study of DNA/small molecule binding interactions
}

\author{
Rongfu Huang, Li-Rong Wang, Liang-Hong Guo* \\ State Key Laboratory of Environmental Chemistry and Ecotoxicology, Research Center for Eco-environmental Sciences, Chinese Academy of Sciences, \\ 18 Shuangqing Road, P.O. Box 2871, Beijing 100085, China
}

\section{A R T I C L E I N F O}

\section{Article history:}

Received 22 April 2010

Received in revised form 17 July 2010

Accepted 22 July 2010

Available online 30 July 2010

\section{Keywords:}

Electrochemiluminescence

Displacement

DNA

Ligand

Binding

\begin{abstract}
A B S T R A C T
Non-covalent binding interactions of small molecules with DNA play important roles in regulating gene expression and gene function. In this work, a highly sensitive electrochemiluminescence (ECL) displacement method has been developed to investigate such interactions, particularly for weak DNA binders. This ECL method relies on a double-stranded DNA film deposited on an indium tin oxide electrode (ITO) surface by layer-by-layer self-assembly. A DNA intercalator, $\left[\mathrm{Ru}(\mathrm{bpy})_{2}(\mathrm{dppz})\right]^{2+}\left(\mathrm{bpy}=2,2^{\prime}\right.$-bipyridine, $\mathrm{dppz}=$ dipyrido[3,2-a:2'3'-c]phenazine), is employed as the ECL signal indicator. If a test compound competes with the indicator for the same binding sites in DNA, it would displace the indicator from the film and reduce ECL signal. The new method was validated by measuring five well-known DNA-binding organic molecules including quinacrine, H33258, thiazole orange, ethidium bromide and 4,6-diamidine2-phenylindole dihydrochloride. Due to high ECL sensitivity, only $0.4 \mu \mathrm{mol} \mathrm{L}^{-1}\left[\mathrm{Ru}(\mathrm{bpy})_{2}(\mathrm{dppz})\right]^{2+}$ was needed in the ECL displacement measurement, which is about 75-fold less than the concentration in the voltammetric measurement. The lowered concentration permitted direct measurement of $\mathrm{IC}_{50}$ values of eight hydroxylated polycyclic aromatic hydrocarbons in their ECL displacement curves and subsequent calculation of their binding constants with DNA. The ECL displacement method is particularly useful for investigating weak DNA binders with limited aqueous solubility.
\end{abstract}

(C) 2010 Elsevier B.V. All rights reserved.

\section{Introduction}

The main roles of DNA in the cells are to maintain and properly express genetic information. Binding of exogenous small molecules with DNA can either activate or inhibit gene expression, transcription, or translation, which is the basis of anti-cancer drugs [1]. Binding interaction with DNA is also the first step in DNA-damaging action or genotoxic process of some carcinogenic chemicals [2,3]. A better understanding of DNA/small molecule interactions is helpful in the rational design of chemo-therapeutic drugs as well as in the study of molecular toxicology of carcinogenic chemicals. A great deal of effort has been made to investigate the binding mode, binding affinity, and sequence selectivity of small molecules with DNA with an aim of establishing quantitative structural relationship.

Intercalation, groove binding, and electrostatic interactions are the three major binding modes of small molecules to DNA [4]. A variety of techniques are commonly used to investigate the interaction between small molecules and DNA, including footprinting, affinity cleavage, NMR, X-ray crystallography, UV-vis spectrophotometry, fluorescence, circular dichroism, and hydrody-

\footnotetext{
* Corresponding author. Tel.: +8610 62849685; fax: +86 1062849685 .

E-mail address: LHGuo@rcees.ac.cn (L.-H. Guo).
}

namic measurements [5,6]. For example, Boger's group developed a rapid, simple, and nondestructive fluorescence intercalator displacement assay for the high throughput assessment of DNAbinding affinity, sequence selectivity, and binding stoichiometry for drug compounds. This method was based on the signal loss derived from the displacement of fluorescent probe, ethidium bromide, or thiazole orange from the DNA of interest [7]. However, some fluorescent organic compounds cannot be studied by this fluorescence assay due to their interference with the indicator.

Electrochemistry provides a simple, sensitive and inexpensive approach for investigating DNA/drug [8-11] and DNA/pollutant interactions $[12,13]$ by monitoring the voltammetric signal of either the compound itself or the guanine bases in DNA. Recently, an electrochemical displacement method was developed by our group to investigate the binding interaction between organic molecules and DNA [14]. In the method, DNA films are deposited on ITO electrodes by layer-by-layer self-assembly. A DNA intercalator, $\left[\mathrm{Ru}(\mathrm{bpy})_{2}(\mathrm{dppz})\right]^{2+}\left(\mathrm{Ru}-\mathrm{dppz}, \mathrm{bpy}=2,2^{\prime}\right.$-bipyridine, $\mathrm{dppz}=$ dipyrido[3,2-a:2' $3^{\prime}$-c]phenazine), is used as a voltammetric signal indicator and allowed to bind to the DNA film. If the tested chemical competes with Ru-dppz for the same binding sites in DNA, it would displace Ru-dppz from DNA and thus reduce its voltammetric signal. From the displacement curve, $\mathrm{IC}_{50}$ (concentration of the chemical to induce $50 \%$ signal inhibition) can be 
obtained, and the binding constant is calculated accordingly. Using this method, 21 hydroxylated polycyclic aromatic hydrocarbons (OH-PAHs) were investigated [15]. It was found that $\mathrm{IC}_{50}$ value of eight of the OH-PAHs was higher than the solubility of these compounds in aqueous solutions. As a result, $\mathrm{IC}_{50}$ and binding constant could not be obtained by the electrochemical displacement measurement.

One way to overcoming the problem is to employ a more sensitive detection method so that a lower concentration of the signal indicator can be used. When the indicator concentration is sufficiently low, $\mathrm{IC}_{50}$ will be obtained before the chemical reaches its solubility limit. Due to its ultra-low background, electrogenerated chemiluminescence or electrochemiluminescence (ECL) is inherently much more sensitive than voltammetric measurements (down to sub-femtomole levels in some cases) [16]. ECL system using $\mathrm{Ru}(\mathrm{bpy})_{3}{ }^{2+}$ or its analogues attached to DNA provides a sensitive detection method [17-19]. Bard's group designed an $\mathrm{Al}_{2}\left(\mathrm{C}_{4} \mathrm{BP}\right)$ thin film to immobilize DNA that was identified by intercalation into double-stranded DNA of a transition metal chelate, $\mathrm{Ru}$ (phen $)_{3}{ }^{2+}$, which emitted light when oxidized electrochemically in the presence of a suitable co-reactant [17]. Additionally, Rusling and co-workers reported that ultra-thin films of the catalytic metallopolymer $\left[\mathrm{Ru}(\mathrm{bpy})_{2}(\mathrm{PVP})_{10}\right]\left(\mathrm{ClO}_{4}\right)_{2}$ and oligonucleotides on electrodes could generate direct ECL signals that were sensitive to hybridization and chemical or enzyme-generated damage of DNA $[18,19]$. According to the literature, ECL of Ru-dppz has been investigated, showing that the signal increased about 1000 times in the presence of DNA [20].

In the current work, an ECL displacement method is developed using the same DNA film and indicator as in our previous work, but ECL signal is measured instead of voltammetric current. Thanks to high ECL sensitivity, adequate signal-to-background (S/B) ratio is achieved even with sub-micromolar concentration of Ru-dppz. The method is validated by measuring the binding constants of five well-known DNA-binding organic compounds. It is then utilized to investigate the DNA-binding constants of the eight OH-PAHs, which were not obtained in the previous work by the electrochemical displacement method.

\section{Experiment section}

\subsection{Reagents}

Calf-thymus double-stranded DNA (CT-DNA, approximately 13K base pairs) and Hoechst 33258 (H33258) were purchased from Merck (San Diego, CA). Thiazole orange (TO), ethidium bromide (EB), poly(diallyldimethylammonium chloride) (PDDA), quinacrine dihydrochloride, 9-hydroxyfluorene (9-OHFLU), 2hydroxybenzo[c]phenanthrene (2-OHBcPh), 2-hydroxyfluorene (2-OHFLU), and tripropylamine (TPA) were obtained from Sigma-Aldrich (St. Louis, MO). 4,6-Diamidine-2-phenylindole dihydrochloride (DAPI) was purchased from Roche (Basel, Switzerland). 5-Hydroxybenzo[c]phenanthrene (5-OHBcPh), 1hydroxybenzo[a]pyrene (1-OHBaP), 4-hydroxybenzo[a]pyrene (4$\mathrm{OHBaP}$ ), and 5-hydroxybenzo[a]pyrene (5-OHBaP) were purchased from Midwest Research Institute (Kansas, MO, USA). 1-Hydroxynaphthalene (1-OHNAP) was obtained from Alfa Aesar (Ward Hill, MA, USA). [Ru(bpy $\left.)_{2}(\mathrm{dppz})\right]\left(\mathrm{BF}_{4}\right)_{2}$ was synthesized according to the published procedure [21] as a racemic mixture.

\subsection{Apparatus}

ECL measurements were performed on a CHI 660b electrochemistry analyzer ( $\mathrm{CH}$ Instruments, Austin, TX) with a Pt counter electrode and an $\mathrm{Ag} / \mathrm{AgCl}\left(3 \mathrm{~mol} \mathrm{~L}^{-1} \mathrm{KCl}\right)$ reference electrode (also

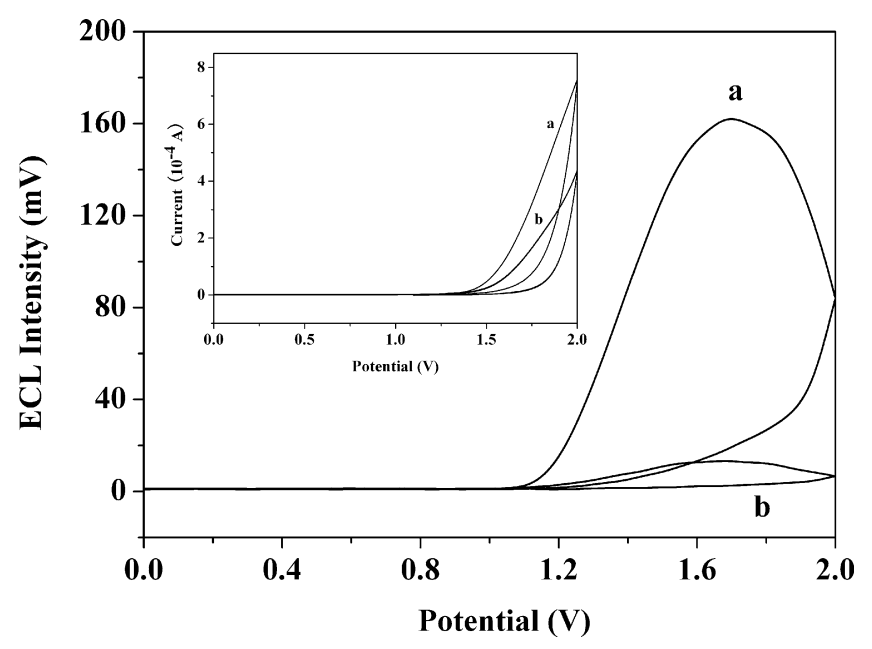

Fig. 1. ECL-potential curves of DNA-modified ITO electrodes in $100 \mathrm{mmol} \mathrm{L}^{-1} \mathrm{TPA}$ (pH 7.4) after reacting with (a) $0.4 \mu \mathrm{mol} \mathrm{L}^{-1} \mathrm{Ru}-\mathrm{dppz}$ and (b) $0 \mu \mathrm{mol} \mathrm{L}^{-1} \mathrm{Ru}-\mathrm{dppz}$. Potential scan rate: $100 \mathrm{mV} \mathrm{s}^{-1}$. Inset is the corresponding voltammogram.

from $\mathrm{CH}$ Instruments). ECL light intensity was collected with an H9306-03 photomultiplier tube (PMT, Hamamatsu, Japan) placed directly in the front of the transparent electrochemical cell. Both the cell and PMT were enclosed in a light-tight box. The voltage signal was put into the auxiliary signal recording port on the $\mathrm{CHI}$ 660b analyzer.

\subsection{Procedures}

All the solutions were prepared in high-purity water from a Millipore Milli-Q Biocel water purification system (Billerica, MA). Tin-doped indium oxide (ITO) electrodes were prepared and cleaned as described before [22]. DNA films on ITO electrodes were assembled by layer-by-layer electrostatic adsorption. Cleaned ITO electrodes were first reacted with $20 \mu \mathrm{L}$ PDDA $\left(2.0 \mathrm{mg} \mathrm{mL}^{-1}\right.$ in $20 \mathrm{mmol} \mathrm{L}^{-1}$ phosphate buffer, $\mathrm{pH} 7.4$ ) on an area of $0.5 \mathrm{~cm} \times 1.0 \mathrm{~cm}$ for $1.5 \mathrm{~h}$ and then washed carefully. The PDDA modified electrode was then incubated with $20 \mu \mathrm{L}$ of $0.2 \mathrm{mg} \mathrm{mL}^{-1}$ calf-thymus DNA in $20 \mathrm{mmol} \mathrm{L}^{-1}$ phosphate ( $\mathrm{pH} \mathrm{7.4)}$ on the same area for $30 \mathrm{~min}$. This is denoted as the ITO/PDDA/DNA electrode. Finally, Ru-dppz alone or Ru-dppz with an organic compound was reacted with the DNA film for $60 \mathrm{~min}$, and unbound chemicals were washed off with water before ECL measurement. The electrode area in contact with the electrolyte for ECL measurement was $0.25 \mathrm{~cm}^{2}$.

\section{Results and discussion}

To conduct ECL displacement experiments, DNA films were first prepared on ITO electrodes by layer-by-layer electrostatic selfassembly [23]. Due to the presence of surface oxide groups, ITO is negatively charged in neutral pH. PDDA, a cationic polymer, can be deposited on ITO surface by electrostatic attraction. The polymer not only neutralizes the negative charges on the surface, but also brings extra positive charges to it. As a result, a second layer of negatively charged DNA can be assembled on the surface. After DNA film assembly, Ru-dppz was allowed to bind to the DNA film and produce ECL signal when measured in a co-reactant solution. Fig. 1 illustrates ECL-potential profile of Ru-dppz incorporated into the DNA film on ITO. The onset of luminescence occurs near $1.1 \mathrm{~V}$ where Ru-dppz gets oxidized. Light intensity keeps rising with potential scan, and peaks at $1.7 \mathrm{~V}$ (Fig. 1a). These results are similar to previous work [24]. According to the commonly accepted ECL mechanism, it can be assumed that Ru-dppz ${ }^{2+}$ is oxidized on ITO to $\mathrm{Ru}-\mathrm{dppz} \mathrm{z}^{3+}$. And TPA is oxidized to TPA ${ }^{+}$, either electrochemically or 


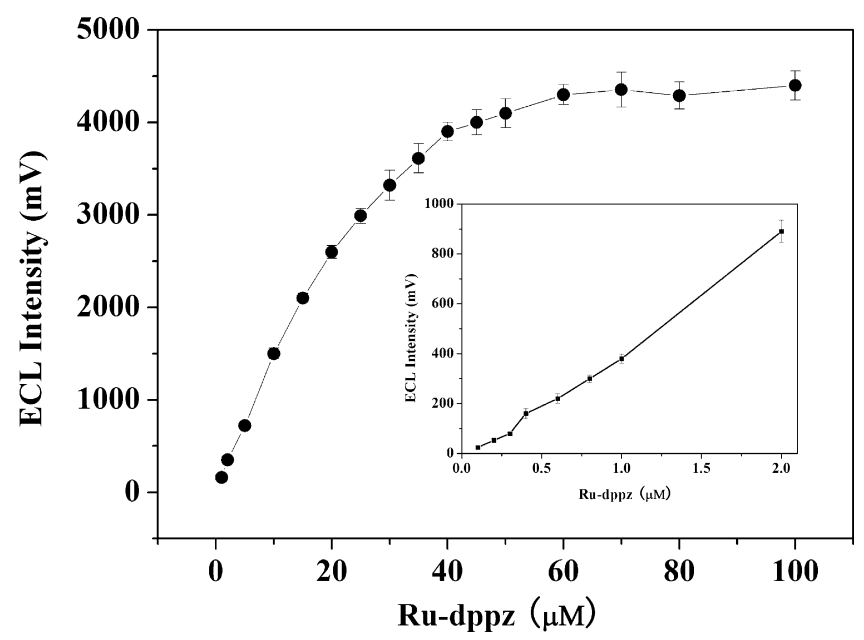

Fig. 2. Plot of peak ECL intensity of Ru-dppz bound to DNA-modified ITO electrode as a function of Ru-dppz concentration in reaction solution. Inset is the plot at lower Ru-dppz concentrations at higher PMT voltage. ECL was measured in $100 \mathrm{mmol} \mathrm{L}^{-1}$ $\mathrm{TPA}$ ( $\mathrm{pH}$ 7.4). Potential scan rate: $100 \mathrm{mV} \mathrm{s}^{-1}$.

chemically, which then deprotonates to become TPA $\bullet$. Light emission is generated after the highly reducing radical species reacts with Ru-dppz ${ }^{3+}$ to form the excited state of Ru-dppz ${ }^{2+}$. At low oxidizing potentials, Ru-dppz gets oxidized to Ru-dppz ${ }^{3+}$, which further catalyzes TPA oxidation. At high anodic potentials, TPA is oxidized directly on ITO electrode, leading to higher emission. Coincidentally, the background emission of the DNA electrode without Ru-dppz also exhibits a peak at $1.7 \mathrm{~V}$ (Fig. 1b), which probably comes from TPA oxidation products.

To select an indicator concentration for ECL displacement measurement, the relationship between ECL and Ru-dppz concentration was investigated. As depicted in Fig. 2, the relationship follows typical adsorption isotherm. ECL peak intensity at $1.7 \mathrm{~V}$ initially increases with Ru-dppz concentrations up to $40 \mu \mathrm{mol} \mathrm{L}^{-1}$, and then levels off at higher Ru-dppz concentrations. The plateau indicates saturation of Ru-dppz binding sites in the DNA film. With the use of Scatchard analysis [25], the binding constant of Ru-dppz with DNA is estimated as $2.4 \times 10^{6} \mathrm{~mol}^{-1}$, which agrees reasonably well with those reported in the literature [26,27]. For displacement measurement, the indicator concentration should be kept as low as possible, as long as S/B is adequate. After examining the results in Fig. 2, a concentration of $0.4 \mu \mathrm{mol} \mathrm{L}^{-1} \mathrm{Ru}$-dppz is selected, at which $\mathrm{S} / \mathrm{B}$ ratio is 16 . This indicator concentration is 75 times lower than the one used in previous electrochemical displacement measurement [14].

To validate this new method, five known DNA binders were examined, including two DNA groove-binders (DAPI and H33258) and three DNA intercalators (TO, EB, and quinacrine). DNAmodified electrodes were incubated in a solution containing $0.4 \mu \mathrm{mol} \mathrm{L}^{-1} \mathrm{Ru}-\mathrm{dppz}$ and a DNA binder of various concentrations. After the reaction, ECL emission of the electrode was measured in a TPA solution. Fig. 3 illustrates ECL-potential curves for various concentrations of DAPI, which shows that when DAPI concentration

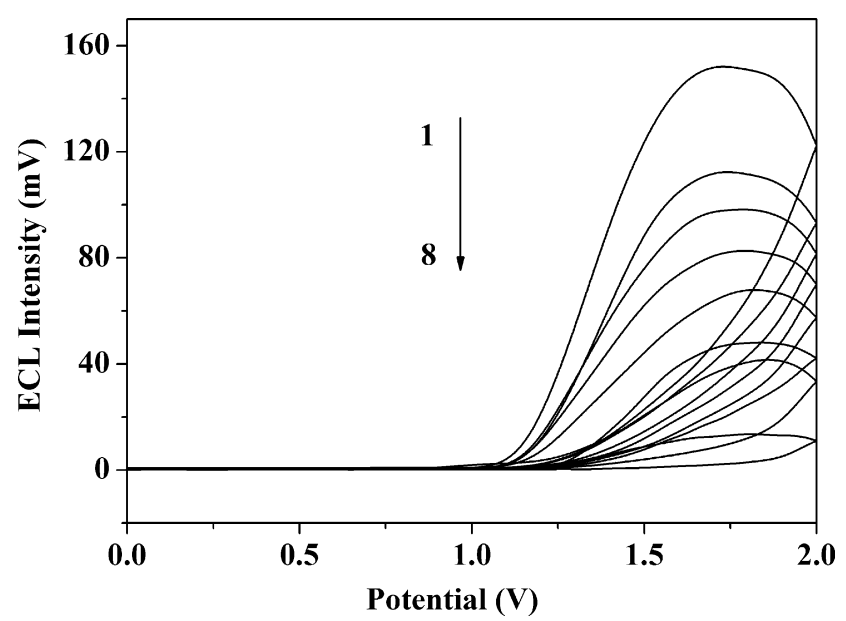

Fig. 3. ECL-potential curves of DNA-modified ITO electrode in $100 \mathrm{mmol} \mathrm{L}^{-1}$ TPA ( $\mathrm{pH}$ 7.4) after reacting with a mixed solution of $0.4 \mu \mathrm{mol} \mathrm{L}^{-1} \mathrm{Ru}-\mathrm{dppz}$ and DAPI $\left(0,0.01,0.02,0.05,0.1,0.2,0.5\right.$ and $1 \mu \mathrm{mol} \mathrm{L}^{-1}$ from 1 to 8$)$. Potential scan rate: $100 \mathrm{mV} \mathrm{s}^{-1}$.

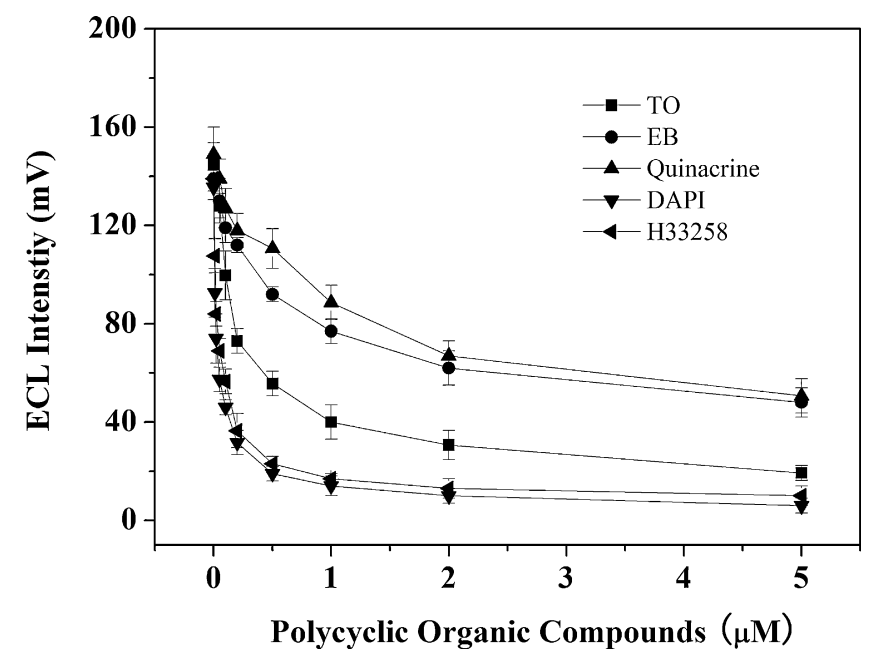

Fig. 4. Plots of ECL peak intensity of DNA-modified ITO electrodes as a function of the concentration of DNA binders in the mixed solution with $0.4 \mu \mathrm{mol} \mathrm{L}^{-1} \mathrm{Ru}-\mathrm{dppz}$ ECL was measured in $100 \mathrm{mmol} \mathrm{L}^{-1} \mathrm{TPA}\left(\mathrm{pH} 7.4\right.$ ). Potential scan rate: $100 \mathrm{mV} \mathrm{s}^{-1}$.

is increased, ECL intensity decreases progressively. The intensity approaches the background level when DAPI concentration reaches $1 \mu \mathrm{mol} \mathrm{L}^{-1}$. All the other four DNA binders have displayed similar concentration dependence, but the degree of signal reduction varies with each compound. For EB and quinacrine, addition of even $1 \mu \mathrm{mol} \mathrm{L}^{-1}$ compound into the solution results in less than $50 \%$ loss in ECL signal, whereas the two minor groove-binders induce nearly $100 \%$ displacement. The results indicate different binding affinity between the compounds and DNA. After background subtraction, the plot of ECL peak intensity at $1.7 \mathrm{~V}$ against the compound concentration resembles a typical competition curve (Fig. 4). From the plot, $\mathrm{IC}_{50}$ values are obtained and the binding constants $\left(K_{\mathrm{b}}\right)$ of the

Table 1

$\mathrm{IC}_{50}$ and binding constants of five known DNA binders.

\begin{tabular}{|c|c|c|c|c|}
\hline & $\mathrm{IC}_{50}\left(\mu \mathrm{mol} \mathrm{L}^{-1}\right)$ & $K_{\mathrm{b}}\left(10^{6} \mathrm{~mol}^{-1}\right)$ & $\mathrm{K}_{\mathrm{EC}}\left(10^{6} \mathrm{~mol}^{-1}\right)$ & $K_{\text {ref }}\left(10^{6} \mathrm{~mol}^{-1}\right)$ \\
\hline DAPI & $0.054 \pm 0.003$ & $36 \pm 1.4$ & 12.3 & 29 [29] \\
\hline H33258 & $0.07 \pm 0.008$ & $28 \pm 3.3$ & 10 & $11-97[30]$ \\
\hline TO & $029 \pm 0.06$ & $6.9 \pm 0.95$ & 2.7 & $1.0-1.3$ [7] \\
\hline $\mathrm{EB}$ & $3.2 \pm 1.2$ & $0.61 \pm 0.23$ & 0.41 & $0.56[31]$ \\
\hline Quinance & $3.6 \pm 0.91$ & $0.54 \pm 0.14$ & 0.43 & $0.2-0.7[32]$ \\
\hline
\end{tabular}

$K_{\mathrm{EC}}$ : binding constant measured in previous work by the voltammetric method [14] and $K_{\mathrm{ref}}$ : the reported value in the literature. 


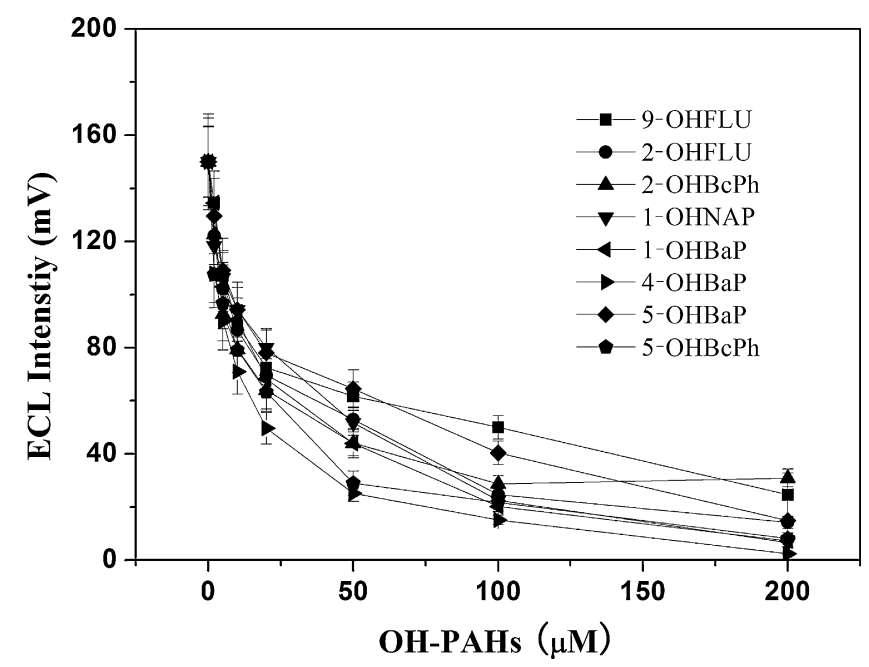

Fig. 5. Plots of ECL peak intensity of DNA-modified ITO electrodes as a function of the concentration of OH-PAHs in the mixed solution with $0.4 \mu \mathrm{mol} \mathrm{L}^{-1} \mathrm{Ru}-\mathrm{dppz}$. ECL

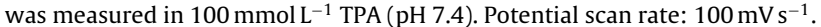

five polycyclic organic compounds with DNA in the film are calculated according to the formula $K_{\mathrm{b}}=\left(1+K_{\mathrm{i}}[\mathrm{Ru}-\mathrm{dpp}]\right) / \mathrm{IC}_{50}$, where $K_{\mathrm{i}}$ is the binding constant of Ru-dppz with DNA [28]. As can be seen in Table 1, the binding constant of the two intercalators, EB and quinacrine, are much lower than the two groove-binders, DAPI and H33258. The values are reasonable for DNA intercalators and groove-binders, and are also comparable to those measured by the established methods. The comparable data obtained by this new method prove that it is a valid approach to measure the binding constant of small molecules with DNA. Additionally, the $\mathrm{IC}_{50}$ values of the two DNA intercalators are less than $2 \mu \mathrm{mol} \mathrm{L}^{-1}$ in the ECL measurement, but more than $150 \mu \mathrm{mol} \mathrm{L}^{-1}$ in the previous electrochemical displacement experiment. The lowered $\mathrm{IC}_{50}$ values suggest it is now possible to investigate by the new method chemicals with limited aqueous solubility.

After the ECL displacement method was established and validated, some OH-PAHs were investigated. These polycyclic organic compounds have been examined before by the electrochemical displacement method [15]. Due to the use of relatively high indicator concentration, weak DNA-binding affinity and low aqueous solubility, $\mathrm{IC}_{50}$ of eight $\mathrm{OH}-\mathrm{PAHs}$ was not reached even with the most concentrated solution. These OH-PAHs include 1-OHNAP, 2OHFLU, 9-OHFLU, 2-OHBcPh, 5-OHBcPh, 1-OHBaP, 4-OHBaP, and 5 -OHBaP. They were investigated by the ECL displacement method, using $0.4 \mu \mathrm{mol} \mathrm{L}^{-1} \mathrm{Ru}-\mathrm{dppz}$ as indicator. As expected, a plot of the ECL intensity against $\mathrm{OH}-\mathrm{PAH}$ concentration produces a displacement curve for each compound. And all the eight $\mathrm{OH}-\mathrm{PAHs}$ inhibited ECL signal by more than $50 \%$ when the concentration was over $20 \mu \mathrm{mol} \mathrm{L}^{-1}$ (Fig. 5). From the curve, $\mathrm{IC}_{50}$ values were measured directly, and the binding constants calculated by the formula described above. As listed in Table $2, K_{\mathrm{b}}$ numbers fall in the range of $1.07 \times 10^{5}$ to $1.84 \times 10^{5} \mathrm{~mol}^{-1}$.

Table 2

$\mathrm{IC}_{50}$ and binding constants of eight $\mathrm{OH}-\mathrm{PAHs}$ with DNA.

\begin{tabular}{lcc}
\hline OH-PAH & $\mathrm{IC}_{50}\left(\mu \mathrm{mol} \mathrm{L}^{-1}\right)$ & $K\left(10^{5} \mathrm{~mol}^{-1}\right)$ \\
\hline 9-OHFLU & $18.2 \pm 3.0$ & $1.07 \pm 0.18$ \\
2-OHFLU & $15.4 \pm 1.4$ & $1.27 \pm 0.12$ \\
2-OHBcPh & $12.6 \pm 1.1$ & $1.55 \pm 0.14$ \\
1-OHNAP & $11.6 \pm 0.9$ & $1.69 \pm 0.09$ \\
1-OHBaP & $16.4 \pm 2.3$ & $1.18 \pm 0.17$ \\
4-OHBaP & $11.1 \pm 0.5$ & $1.76 \pm 0.08$ \\
5-OHBaP & $10.7 \pm 0.8$ & $1.84 \pm 0.14$ \\
5-OHBcPh & $13.5 \pm 2.1$ & $1.45 \pm 0.23$ \\
\hline
\end{tabular}

\section{Conclusions}

In conclusion, we have developed a highly sensitive ECL displacement method to investigate the binding interaction of small molecules with DNA. Employing ECL as the signal detection technique, the indicator concentration in the displacement measurement was reduced by 75 -fold by comparison with previously reported electrochemical method. The lowered concentration enabled investigation of some OH-PAHs that are weak DNA binders and only slightly soluble in aqueous solutions. Although only $\mathrm{OH}-$ PAHs were investigated in our present work, this method can be extended to the study of a variety of weak DNA-binding ligands with limited aqueous solubility, which cannot be studied by other less sensitive methods. Since the detected signal is light emission, the new method is not prone to interference from electrochemical oxidation of the DNA bases or the test compound, which has been found to be problematic in the voltammetric measurement. ECL method also offers an alternative to the more popular fluorescence method, as some of the aromatic chemicals share similar fluorescence properties with the fluorescent indicator and cannot be studied by fluorescence measurement. As reported recently by Barton and co-workers [33,34], Ru-dppz exhibited significantly enhanced luminescence when it bound to mismatched DNA in comparison with the complementary DNA. It was suggested that this complex could be utilized as a sensitive reporter for DNA defects. We hope that the ECL displacement method developed in our work, when in combination with some structurally well-defined ECL indicators, will allow us to investigate the binding mode, binding affinity, and sequence selectivity of a series of structurally similar chemicals with DNA so as to establish some structure-property relationship.

\section{Acknowledgement}

This work was supported by the National Natural Science Foundation of China (grant number 20890112, 20825519, 20621703).

\section{References}

[1] M.J. Browne, P.L. Thurlby, Genomes Molecular Biology and Drug Discovery, Academic, London, 1996.

[2] T.M. Penning, M.E. Burcynski, C.F. Hung, K.D. McCoull, N.T. Palackal, L.S. Tsuruda, Chem. Res. Toxicol. 12 (1999) 1-18.

[3] J. Szeliga, A. Dipple, Chem. Res. Toxicol. 11 (1998) 1-11.

[4] B.M. Zeglis, V.C. Pierre, J.K. Barton, Chem. Commun. 44 (2007) 4565-4579.

[5] P.B. Dervan, Bioorgan. Med. Chem. 9 (2001) 2215-2235.

[6] D.E. Graves, L.M. Velea, Curr. Org. Chem. 4 (2000) 915-929.

[7] D.L. Boger, B.E. Fink, S.R. Brunette, W.C. Tse, M.P. Hedrick, J. Am. Chem. Soc. 123 (2001) 5878-5891.

[8] A. Erdem, M. Ozsoz, Electroanalysis 14 (2002) 965-974.

[9] M. Fojta, Electroanalysis 14 (2002) 1449-1463.

[10] S. Rauf, H. Nawaz, K. Akhtar, M.A. Ghauri, A.M. Khalid, Biosens. Bioelectron. 22 (2007) 2471-2477.

[11] B. Dogan-Topal, B. Uslu, S.A. Ozkan, Biosens. Bioelectron. 24 (2009) 2358-2364

[12] J. Wang, M. Chicharro, G. Rivas, X. Cai, N. Dontha, P.A.M. Farias, H. Shiraishi, Anal. Chem. 68 (1996) 2251-2254.

[13] J. Wang, G. Rivas, D. Luo, X. Cai, F.S. Valera, N. Dontha, Anal. Chem. 68 (1996) 4365-4369.

[14] L.R. Wang, N. Qu, L.H. Guo, Anal. Chem. 80 (2008) 3910-3914.

[15] L.R. Wang, Y. Yang, J.W. Chen, L.H. Guo, Toxicology 262 (2009) 250-257.

[16] A.J. Bard, Electrogenerated Chemiluminescence, Marcel Dekker Inc., New York, 2004.

[17] X.Xu, H.C. Yang, T.E. Mallouk, A.J. Bard, J. Am. Chem. Soc. 116(1994) 8386-8387.

[18] L. Dennany, R.J. Forster, J.F. Rusling, J. Am. Chem. Soc. 125 (2003) 5213-5218.

[19] M. So, E.G. Hvastkovs, J.B. Schenkman, J.F. Rusling, Biosens. Bioelectron. 23 (2007) 492-498.

[20] L. Hu, Z. Bian, H. Li, S. Han, Y. Yuan, L. Gao, G. Xu, Anal. Chem. 81 (2009) 9807-9811.

[21] S. Musumeci, E. Rizzarelli, I. Fragala, S. Sammartano, R.P. Bonomo, Inorg. Chim. Acta 7 (1973) 660-664.

[22] C. Li, S.L. Liu, L.H. Guo, D.P. Chen, Chem. Commun. 7 (2005) 23-28.

[23] M.Y. Wei, L.H. Guo, H. Chen, Mikrochim. Acta 155 (2006) 409-414.

[24] R. Wilson, H. Akhavan-Tafti, R. Desilva, A.P. Schaap, Electroanalysis 13 (2001) 1083-1092. 
[25] G. Scatchard, Ann. N.Y. Acad. Sci. 51 (1949) 660-672.

[26] D.L. Carlson, D.H. Huchital, E.J. Mantilla, R.D. Sheardy, W.R. Murphy, J. Am. Chem. Soc. 115 (1993) 6424-6425.

[27] A.E. Friedman, J.C. Chambron, J.P. Sauvage, N.J. Turro, J.K. Barton, J. Am. Chem. Soc. 112 (1990) 4960-4962.

[28] Y.C. Cheng, W.H. Prusoff, Biochem. Pharmacol. 22 (1973) 3099-3108.

[29] F.G. Loontiens, L.W. McLaughlin, S. Diekmann, R.M. Glegg, Biochemistry 30 (1991) 182-189.
[30] F. Rosu, V. Gabelica, C. Houssier, E.D. Pauw, Nucleic Acids Res. 30 (2002) e82.

[31] S.H. Minasyana, L.A. Tavadyana, A.P. Antonyanb, H.G. Davtyanb, M.A. Parsadanyanb, P.O. Vardevanyanb, Bioelectrochemistry 68 (2006) 48-55.

[32] M. Aslanoglu, G. Ayne, Anal. Bioanal. Chem. 380 (2004) 658-663.

[33] M.H. Lim, H. Song, E.D. Olmon, E.E. Dervan, J.K. Barton, Inorg. Chem. 48 (2009) 5395-5397.

[34] B.M. Zeglis, V.C. Pierre, J.T. Kaiser, J.K. Barton, Biochemistry 48 (2009) 4247-4253. 